\title{
Uterine natural killer cells initiate spiral artery remodeling in human pregnancy
}

DOI:

10.1096/fj.12-210310

\section{Document Version}

Accepted author manuscript

Link to publication record in Manchester Research Explorer

\section{Citation for published version (APA):}

Robson, A., Harris, L. K., Innes, B. A., Lash, G. E., Aljunaidy, M. M., Aplin, J. D., Baker, P. N., Robson, S. C., \& Bulmer, J. N. (2012). Uterine natural killer cells initiate spiral artery remodeling in human pregnancy. Faseb Journal, 26(12), 4876-4885. https://doi.org/10.1096/fj.12-210310

\section{Published in:}

Faseb Journal

\section{Citing this paper}

Please note that where the full-text provided on Manchester Research Explorer is the Author Accepted Manuscript or Proof version this may differ from the final Published version. If citing, it is advised that you check and use the publisher's definitive version.

\section{General rights}

Copyright and moral rights for the publications made accessible in the Research Explorer are retained by the authors and/or other copyright owners and it is a condition of accessing publications that users recognise and abide by the legal requirements associated with these rights.

\section{Takedown policy}

If you believe that this document breaches copyright please refer to the University of Manchester's Takedown Procedures [http://man.ac.uk/04Y6Bo] or contact uml.scholarlycommunications@manchester.ac.uk providing relevant details, so we can investigate your claim.

\section{OPEN ACCESS}




\section{Uterine natural killer cells initiate spiral artery remodelling in human pregnancy}

A Robson ${ }^{1,4}$; LK Harris ${ }^{2,4}$; BA Innes ${ }^{1}$; GE Lash $^{1}$; MM Aljunaidy ${ }^{2}$; JD Aplin ${ }^{2}$; PN Baker ${ }^{2,3}$; SC Robson ${ }^{1}$; JN Bulmer ${ }^{1,5}$

5

${ }^{1}$ Reproductive and Vascular Biology Group, Institute of Cellular Medicine, Newcastle University, Newcastle upon Tyne, UK; ${ }^{2}$ Maternal and Fetal Health Research Centre, University of Manchester, UK; ${ }^{3}$ Department of Obstetrics and Gynecology, University of Alberta, Edmonton, Alberta. Canada

10

${ }^{4}$ These authors contributed equally to the work

${ }^{5}$ Corresponding Author

Dr Judith N Bulmer

15 Reproductive and Vascular Biology Group

Institute of Cellular Medicine

$3^{\text {rd }}$ Floor, William Leech Building

Newcastle University

Newcastle upon Tyne

20 NE2 4HH, UK

Phone: +44 191222 5213/Fax: +44 1912225066

Email: j.n.bulmer@ncl.ac.uk

Running title: uNK cells in spiral artery remodelling 
Non-standard abbreviations

Ang Angiopoietin

CM Conditioned medium

30 CPA Chorionic plate artery

ECM Extracellular matrix

EVT Extravillous trophoblast cells

MMP Matrix metalloproteinase

pbNK Peripheral blood natural killer cell

$35 \quad \mathrm{SpA} \quad$ Spiral artery

TGF Transforming growth factor

uNK Uterine natural killer

VEGF Vascular endothelial growth factor

VSMC Vascular smooth muscle cell

40 


\begin{abstract}
Uterine spiral artery remodelling is required for successful human pregnancy; impaired remodelling being associated with pregnancy complications, including late miscarriage, preeclampsia and fetal growth restriction. The molecular triggers of remodelling are not known

45 but it is now clear that there are 'trophoblast-independent' and 'trophoblast-dependent' stages. Uterine natural killer ( $\mathrm{uNK}$ ) cells are abundant in decidualised endometrium in early pregnancy; they surround spiral arteries and secrete a range of angiogenic growth factors. We hypothesised that uNK cells mediate initial stages of spiral artery remodelling. uNK cells and extravillous trophoblast cells (EVT) were isolated from early pregnancy decidua and 50 placenta. Chorionic plate arteries from full term placentas and spiral arteries from nonpregnant myometrium were cultured with angiogenic growth factors, or conditioned medium (CM) from uNK cells, EVT or uNK cell/EVT co-cultures. In both vessel models uNK cellCM induced disruption of vascular smooth muscle cells (VSMCs) and break-down of extracellular matrix components. Angiopoietin (Ang)-1, Ang-2, interferon- $\gamma$ and vascular 55 endothelial growth factor-C also disrupted VSMC integrity with an Ang-2 inhibitor abrogating the effect of uNK-CM. These results provide compelling evidence that uNK cells contribute to the early stages of spiral artery remodelling; failure of this process could contribute to pregnancy pathology.
\end{abstract}

60 Keywords: angiogenic growth factors; proteases; vascular smooth muscle cells 


\section{Introduction}

Uterine spiral artery (SpA) remodelling is essential for normal human pregnancy; inadequate remodelling of $\mathrm{SpA}$ is associated with pregnancy complications including pre-eclampsia,

65 fetal growth restriction, pre-term labour and late miscarriage (1-3). In addition to the immediate morbidity and mortality related to these pregnancy complications there are serious future health consequences for both the mother and offspring of these conditions (4-7). As better, earlier, predictive and diagnostic tools for these pregnancy complications are developed it is imperative that the molecular triggers of SpA remodelling are understood to

70 allow development of effective intervention treatments that may pre-empt the clinical symptoms of these conditions.

During the first 20 weeks of gestation, extravillous trophoblast cells (EVT) migrate from placental chorionic villi, invade uterine decidua and myometrium and remodel decidual and

75 superficial myometrial $\mathrm{SpA}$. The musculo-elastic arterial wall is replaced by an amorphous fibrinoid material containing intramural EVT, creating wide bore channels that lack vasomotor control (2). Although trophoblast appears to be essential to complete the SpA remodelling process, the initial stages, including dilatation, endothelial hyperplasia and vacuolisation of medial smooth muscle, occur in the absence of EVT (8-10). These initial

80 morphological changes have been termed 'trophoblast-independent remodelling' and precede 'trophoblast-associated remodelling' events. The mechanisms underlying this trophoblastindependent remodelling are unclear, but are likely to be pregnancy specific: in in vitro studies, trophoblast cells were not able to invade the wall of myometrial SpA taken at the time of hysterectomy (non-pregnant), but could invade the wall of pregnant myometrial SpA

85 taken at elective Caesarean section at term (11). Evidence from mouse studies suggests a role for interferon gamma (IFN- $\gamma$ ) secreted by uterine natural killer ( $\mathrm{UNK}$ ) cells in SpA remodelling in the absence of excessive EVT invasion (12-15).

Uterine NK cells are present in high numbers during early human pregnancy and represent up

90 to $70 \%$ of the decidual leukocyte population (16). They accumulate in and around SpA in the first trimester of normal pregnancy $(10,17)$, declining after 20 weeks gestational age (17). Although their function is unknown, recent work has shown that decidua-associated changes in SpA structure are coincident with influx of uNK cells into the arterial wall (10). As well as IFN- $\gamma$, uNK cells produce an array of angiogenic growth factors including angiopoietin-1

95 (Ang-1), Ang-2 and vascular endothelial growth factor-C (VEGF-C) (18, 19), all of which 
can modify vascular networks $(21,21)$. In addition, uNK cells are potent secretors of matrix metalloproteinase-2 (MMP-2) and MMP-9, which have been implicated in decidual vascular remodelling $(10,22)$.

100 Human SpA consist of a single layer of endothelial cells supported by an internal elastic lamina, and a medial layer of tightly packed vascular smooth muscle cells (VSMCs) with associated extracellular matrix (ECM) (23). Although observational in situ studies have suggested a role for uNK cells in trophoblast-independent remodelling, functional studies have not been reported and the underlying mechanisms are not clear. The mechanisms that

105 underpin normal SpA remodelling are not understood and research has focused mainly on the role of trophoblast in this process. We suggest that the uNK cells play an essential early role; defective function of uNK cells in early pregnancy may therefore impact on long term health via pregnancy complications. We hypothesised that for EVT cells to infiltrate and remodel the vessel wall, the medial VSMC layers and their surrounding ECM must be destabilised, 110 and that uNK cells play a role in this process in human pregnancy through secretion of angiogenic growth factors. To test this hypothesis two different ex vivo models were used: a high throughput chorionic plate artery model and a more physiological non-pregnant myometrial SpA model. Both models were assessed by immunohistochemistry for disruption of the VSMC morphology and organisation after treatment with different agents of interest. 


\section{Methods}

\section{Sample collection}

Placental and decidual samples were obtained at 8-10 and 12-14 weeks gestational age (8-10 weeks $n=50 ; 12-14$ weeks $n=20$ ) from women undergoing elective surgical termination of 120 pregnancy at the Royal Victoria Infirmary. Chorionic plate artery segments were obtained from normal term placenta $(\mathrm{n}=50)$. Myometrial biopsies were obtained from healthy, nonpregnant, pre-menopausal women undergoing hysterectomy at St. Mary's Hospital, Manchester $(n=25)$. Local ethical approval was obtained and all subjects gave informed written consent (NRES committee North East - Sunderland, approval: 07/H0904/74 and

125 Greater Manchester North, approval: 08/H1011/71).

\section{Isolation and culture of CD56+ cells}

Uterine NK cell-enriched isolates were prepared by enzymatic disaggregation and positive MidiMACS immunomagnetic selection (MACS, Miltenyi Biotec, Surrey, UK) as described

130 previously $(19,24)$. Briefly, decidual tissue was finely minced, incubated in DNase/collagenase (both from Sigma Chemical Co., Poole, Dorset, UK), allowed to adhere overnight and subjected to positive immunomagnetic selection (MidiMACS, Miltenyi Biotec., Surrey, UK) with anti-CD56 (Coulter, High Wycombe, UK) to obtain CD56+ cell suspensions. To prepare uNK cell-conditioned medium (UNK-CM, 1 x $10^{5}$ cells/100 $\mu 1$ were 135 cultured in a 96 well plate in RPMI1640 complete medium containing $10 \%$ fetal bovine serum (FBS), $1 \%$ penicillin/streptomycin and 1\% amphotericin (all from Sigma Chemical Co.). After $24 \mathrm{~h}$ the conditioned medium (CM) was removed, centrifuged to eliminate cell debris, and stored at $-80^{\circ} \mathrm{C}$. Cell purity was tested routinely by immunocytochemical staining of cell smears and was consistently $>95 \%$. Viability of uNK cells was assessed after $24 \mathrm{~h}$ by 140 trypan blue exclusion and was consistently $>95 \%$.

\section{Isolation of extravillous trophoblast}

EVT were isolated from first trimester placenta as previously described $(25,26) .1 \times 10^{6}$ cells/ml were cultured for $24 \mathrm{~h}$ in a 24 well plate in DMEM:Ham's F12 supplemented with $14510 \%$ FBS, $2 \mathrm{mM}$ glutamine, 100 units $/ \mathrm{ml}$ penicillin and $0.1 \mathrm{mg} / \mathrm{ml}$ streptomycin (all from Sigma) (DMEM:Ham's F12 complete medium) on growth factor-reduced Matrigel (BD Biosciences, Franklin Lakes, NJ, USA); conditioned medium (EVT-CM) was then harvested. Cell purity was tested by immunostaining for HLA-G and cytokeratin 7 as described 
previously (25) and viability was assessed by exclusion of trypan blue; both viability and purity was consistently $>95 \%$.

\section{Uterine natural killer and extravillous trophoblast cell co-culture}

To prepare uNK cell/EVT co-culture conditioned medium (UNK/EVT-CM) $1 \times 10^{6}$ EVT cells were cultured in DMEM:Ham's F12 complete medium in a 24 well plate overnight prior to

155 addition of $1 \times 10^{6}$ uNK cells in DMEM:Ham's F12 complete medium to a total volume of $1 \mathrm{ml}$ (26). After $24 \mathrm{~h}$ co-culture the conditioned medium (uNK/EVT-CM) was removed, centrifuged to eliminate cell debris, and stored at $-80^{\circ} \mathrm{C}$. Viability of co-cultures was consistently $>95 \%$.

\section{Peripheral blood NK cells}

Heparinised venous blood was added to phosphate buffered saline (PBS) in a 1:1 ratio, subjected to Lymphoprep $^{\mathrm{TM}}$ (Nycomed Pharma, Oslo, Norway) to obtain a white blood cell fraction, and then to MidiMACS positive immunoselection of CD56+ cells as described above for isolation of uNK cells. $1 \times 10^{5}$ cells/100 $\mu$ l RPMI complete medium were cultured 165 for $24 \mathrm{~h}$ and conditioned medium (pbNK-CM) collected as above. Purity and viability was assessed in the residual cells by immunostaining of cell smears and trypan blue exclusion and was consistently $>95 \%$.

\section{Cell line culture}

170 The SGHPL-4 cell line was a kind gift from Professor Guy Whitley (St George's Medical School, University of London, UK). This cell line is derived from primary first trimester extravillous trophoblast cells transfected with the early region of SV40; characterisation has confirmed an EVT-like phenotype $(27,28)$. Cells were cultured in Ham's F10 medium supplemented with $10 \% \mathrm{FBS}, 2 \mathrm{mM}$ glutamine, 100 units $/ \mathrm{ml}$ penicillin and $0.1 \mathrm{mg} / \mathrm{ml}$ 175 streptomycin (all from Sigma).

\section{Chorionic plate artery model}

Intact chorionic plate artery (CPA) segments $(5 \mathrm{~mm})$ were dissected from normal term placenta, cultured in $5 \% \mathrm{CO}_{2}$ at $37^{\circ} \mathrm{C}$ and incubated at $37^{\circ} \mathrm{C}$ in $5 \% \mathrm{CO}_{2}$ with: (A) $20 \%(\mathrm{v} / \mathrm{v})$

180 24h uNK-CM (in RPMI1640; 8-10 and 12-14 weeks gestation; n=6 each gestational age group); (B) 20\% (v/v) 24h EVT-CM (in DMEM:Ham's F12; 8-10 and 12-14 weeks gestation; $\mathrm{n}=6$ each gestational age group); (C) $20 \%$ (v/v) $24 \mathrm{~h}$ uNK/EVT-CM (in 
DMEM:Ham's F12; 8-10 and 12-14 weeks gestation; n=6 each gestational age group); (D) 1ng/ml and 10ng/ml VEGF-A (R\&D Systems, Abingdon, UK; n=6); (E) 1ng/ml and 10ng/ml

185 VEGF-C (R\&D Systems; n=6); (F) 1ng/ml and 10ng/ml Ang-1 (R\&D Systems; n=6); (G) 1ng/ml and 10ng/ml Ang-2 (R\&D Systems; n=6); (H) 1ng/ml and 10ng/ml IFN- $\gamma$ (R\&D Systems; n=6); (I) 20\% (v/v) uNK-CM (8-10 weeks gestation) + neutralising antibody to Ang-1 (1 $\mu \mathrm{g} / \mathrm{ml}$; Millipore, Watford, UK; n=5); (J) 20\% (v/v) uNK-CM (8-10 weeks

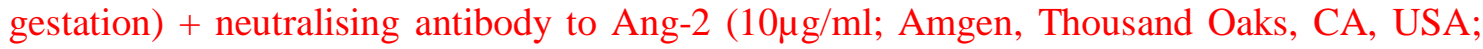

$190 \mathrm{n}=5)$; (K) 20\% (v/v) uNK-CM (8-10 weeks gestation) + neutralising antibody to IFN- $\gamma$ $(2 \mu \mathrm{g} / \mathrm{ml}$; R\&D Systems; n=5); (L) 20\% (v/v) uNK-CM (8-10 weeks gestation) + neutralising

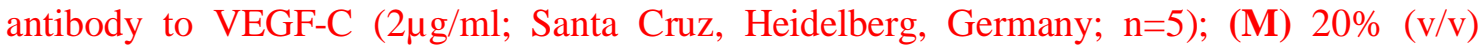
pbNK-CM (in RPMI1640; n=6); (N) RPMI medium control (n=6).

195 The medium was changed every $48 \mathrm{~h}$. CPA were harvested after $120 \mathrm{~h}$, fixed in $10 \%$ neutral buffered formalin and embedded in paraffin wax for immunohistochemistry. $3 \mu \mathrm{M}$ serial sections of CPA were immunostained using an avidin biotin peroxidise technique for CD31 (Table 1) to confirm endothelial integrity after culture; CD31-negative vessels were excluded from this study.

\section{Myometrial spiral artery model}

SpA were dissected from the superficial and middle layers of the myometrium and cultured in DMEM:F12 complete medium for $72 \mathrm{~h}$ as described previously (11) in the presence or absence of $20 \%$ (v/v) CM or recombinant growth factors, as described above for the

205 chorionic plate artery model. The role of proteases was examined by incubation of SpA with $20 \%$ (v/v) uNK-CM with and without a broad spectrum MMP inhibitor (NNGH, 50 $\mu \mathrm{mol} / \mathrm{L}$; Enzo Life Sciences, Exeter, UK). The ability of uNK-CM to facilitate trophoblast cell invasion was examined by incubation of SpA with uNK-CM for 48h, followed by transfer of SpA into unconditioned (control) medium containing SGHPL-4 trophoblast cells $\left(1 \times 10^{5}\right.$

210 cells $/ \mathrm{ml})$. To ensure that trophoblast cells were seeded on top of the very small SpA segments, culture plates were coated with a layer of agarose into which small indentations were made. The arterial segments were placed into the indentations, immobilising them within the wells of the culture plate. Trophoblast cells could then be seeded onto the top of the arteries, without them floating away. SpA were cultured for a further 24 or $48 \mathrm{~h}$, then were 215 snap frozen and embedded in OCT (Cell Path, Newton, UK). 


\section{Immunofluorescence}

Transverse frozen sections $(10 \mu \mathrm{m})$ of myometrial artery were fixed $(4 \%(\mathrm{v} / \mathrm{v})$ paraformaldehyde in PBS; $20 \mathrm{~min})$, permeabilised (0.1\% (v/v) Triton-X in PBS; $5 \mathrm{~min})$,

220 washed in PBS and immunostained for $\alpha$ smooth muscle actin ( $\alpha$ SMA), laminin, fibronectin, collagen IV and elastin. Antibodies were applied for $1 \mathrm{~h}$ and slides were washed $(3 \times 5$ min; PBS) following each antibody incubation (refer to Table 1 for antibody dilutions). Tissue sections were mounted with Vectashield medium containing propidium iodide and imaged using an Olympus IX70 inverted fluorescence microscope with either a 10x or a 40x oil

225 immersion (Zeiss EC PLAN Neofluar 40X/1.3 oil) objective lens and Axiovision 4.7 image analysis software.

\section{Immunohistochemistry}

Paraffin wax-embedded myometrial tissue sections $(5 \mu \mathrm{m})$ and chorionic plate artery sections

$230(3 \mu \mathrm{m})$ were deparaffinised in xylene and ethanol and subjected to antigen retrieval (Table 1). Endogenous peroxide activity was blocked by incubating slides in $0.5 \%(\mathrm{v} / \mathrm{v})$ hydrogen peroxide in distilled water for $10 \mathrm{~min}$. After three washes in $0.05 \mathrm{M}$ Tris-buffered saline, pH7.6 (TBS), sections were immunostained using a Vector Elite Kit (mouse or rabbit as appropriate; Vector Laboratories, Peterborough, UK) as described previously (19). Primary

235 antibodies (Table 1) were diluted to working concentration in TBS. The reaction was developed by incubation in $0.05 \%(\mathrm{w} / \mathrm{v}) \mathrm{DAB}$ and $0.015 \%(\mathrm{v} / \mathrm{v})$ hydrogen peroxide; sections were then washed in water, lightly counterstained with Mayer's haematoxylin, dehydrated, cleared and mounted in DPX synthetic resin (Raymond Lamb, London, UK).

\section{Morphological assessment of disruption of VSMC organisation}

Chorionic plate arteries were immunostained for myosin heavy chain and the morphological appearances of the muscle layers were assessed blinded to the treatment used. Features assessed were the percentage of VSMC rounding, VSMC layer separation and VSMC misalignment using a score of $1=0-10 \%, 2=10-25 \%, 3=25-50 \%$ and $4=>50 \%$. A VSMC was

245 classified as rounded if it had lost its typical elongated spindled shape. VSMC separation was classified as the appearance of spaces between the different layers of VSMCs. A VSMC was classified as misaligned if it was positioned at a 45 to 90 degree angle to the vessel lumen, rather than being aligned parallel with the circumference of the lumen. Taken together these three parameters provide an indication of the level of VSMC organisation within the vessel model. Isolated myometrial SpA were immunostained for $\alpha \mathrm{SMA}$ and counterstained with 
propidium iodide. The percentage of misaligned or rounded VSMC, or the percentage area of the arterial wall exhibiting disruption was scored to the nearest 5\%. All scoring was blinded and a minimum of 4 sections of each artery were scored to determine a mean value for each vessel.

255

\section{Assessment of inter-observer variability}

Thirty CPA tissue sections were assessed independently by two observers (AR and BAI); concordance was defined as within $5 \%$ of individual values and was $>90 \%$ for grading of the morphological assessment of VSMC organisation in CPA.

\section{Quantification of ECM immunostaining in CPAs}

Digital images of myometrial spiral arteries were captured from each immunostained section using a Nikon Eclipse 80i microscope with a Nikon DS camera system and NIS-Elements software. Using Adobe Photoshop individual chorionic plate arteries were selected using the magnetic lasso tool, copied to a new layer within the image and a stained area identified by eye and selected using the magic wand tool. Other immunopositive areas were then selected using the 'similar' command, with the threshold level set such that all positive areas but no negative areas were selected. The immunopositive areas were then copied into a new layer. The number of pixels in each layer was noted and the positive pixels identified in the immunostained sections were expressed as a percentage of the total number of pixels in the vessel wall for each CPA segment.

\section{Statistical Analysis}

Statistical analyses were performed using the StatView statistical software package (Abacus

275 Concepts, Berkley, CA, USA). Significance was determined using a one-way ANOVA, followed by Fisher's post hoc analysis unless otherwise stated. Differences were considered significant at $P<0.05$. 


\section{uNK cell conditioned medium disrupts VSMC organisation}

Both uNK-CM and EVT-CM from 8-10 weeks gestational age increased rounding of VSMC in CPAs (Figures 1A, 1C, both $P<0.05$ ). In addition, uNK-CM enhanced VSMC layer separation (Figures $1 \mathrm{~B}, 1 \mathrm{C} ; P=0.01$ ). In contrast, there was no increase in rounding of VSMC

285 after culture with uNK/EVT-CM (Figures 1A, 1C) and no increase in VSMC separation was observed with either EVT-CM or uNK/EVT-CM (Figures 1B, 1C). CPAs cultured with CM from 12-14 weeks gestational age samples showed no alteration in VSMC morphology and organisation. There were no changes in alignment of CPA VSMCs after incubation in any of the conditioned media.

uNK-CM enhanced VSMC misalignment, separation of VSMC layers and rounding of VSMC within non-remodelled myometrial vessels (Figures 1D, 1G, $1 \mathrm{~J} ; P<0.01, P<0.001$, $P<0.01)$. Furthermore, this effect was specific to uNK cells, as there was no disruption of myometrial artery VSMC architecture after culture in CM from pbNK cells (Figures 1E, 1H, $2951 \mathrm{~K})$.

\section{uNK cell derived factors disrupt VSMC organisation}

Recombinant human Ang-1, Ang-2, and IFN- $\gamma$ all increased separation of VSMC layers in CPA (Figures 2A, 2D; $P<0.05, P<0.01$ and $P=0.05$, respectively), whereas recombinant

300 human Ang-2, IFN- $\gamma$ and VEGF-C enhanced VSMC rounding (Figures 2B, 2D; $P<0.05$, $P<0.005$ and $P<0.005$, respectively). Activity of these growth factors was only observed at $10 \mathrm{ng} / \mathrm{ml}$ and not at $1 \mathrm{ng} / \mathrm{ml}$. Addition of recombinant TGF- $\beta 1$ or VEGF-A did not alter VSMC separation or rounding (data not shown), and none of the recombinant growth factors altered VSMC alignment. Addition of an Ang-2 neutralising antibody $(1 \mu \mathrm{g} / \mathrm{ml})$ attenuated the

305 uNK-CM induced VSMC separation (Figures 2C, 2D); in contrast, although there was partial abrogation of effect, addition of neutralising antibodies specific for Ang-1 and IFN- $\gamma$ did not significantly reduce uNK-CM induced VSMC separation. Similarly, neutralising antibodies directed against Ang-1, Ang-2 and VEGF-C partially abrogated uNK-CM induced VSMC rounding, as they were not significantly different from control or uNK-CM levels. None of 310 the neutralising antibodies on their own (in the absence of uNK-CM) had any effect of the three parameters investigated (data not shown). 
In the myometrial spiral artery model addition of recombinant human Ang-1 and Ang-2 increased VSMC misalignment (Ang-1 $P<0.01$; Ang-2 $P<0.01$ ), separation of VSMC layers

315 (Ang-1 $P<0.01$; Ang-2 $P<0.01$ ) and rounding of VSMCs (Ang-1 $P<0.01$; Ang-2 $P<0.05$ ) (Figures $3 \mathrm{~A}-3 \mathrm{~F})$; these effects were reversed following inclusion of neutralising antibodies. VEGF-C also modestly enhanced VSMC misalignment $(P<0.01)$ and rounding of VSMCs $(P<0.01)$, but did not induce separation of VSMC layers (Figures 3G-3I). Treatment of SpA with IFN- $\gamma$ induced rounding of VSMCs $(P<0.05)$, but did not alter other parameters of 320 vascular disruption (Figures 3J-3L).

Addition of the pan MMP inhibitor (NNGH) abrogated the effect of uNK-CM on VSMC misalignment, separation of VSMC layers and rounding of VSMCs in the myometrial spiral artery model (Figures 3M-3O; $P<0.05, P<0.01, P<0.001$, respectively).

325

\section{uNK cell derived factors initiate ECM remodelling}

The types of morphological alterations observed in CPA and myometrial arteries are likely to be associated with changes in the extracellular matrix (ECM) components of the vessels. Therefore, myometrial SpA from non-pregnant women were immunostained for $\mathrm{H}$ -

330 caldesmon, fibronectin, collagen IV, elastin and laminin in order to demonstrate ECM components prior to pregnancy and remodelling (Figure 4A). Abundant pericellular expression of collagen IV was observed in the arterial media, along with intense basement membrane staining. Fibronectin expression was observed in the VSMC layers. Intense laminin expression was observed in the endothelial cell basement membrane, with moderate

335 staining in the vessel wall. Elastin expression was detected within the internal elastic lamina, and concentric layers of elastin were observed within the arterial wall, interspersed between layers of VSMC.

To determine whether uNK cell secreted factors altered ECM composition CPA cultured in

340 uNK-CM were assessed for immunostaining and quantity of fibronectin, laminin and collagen IV was quantified using a pixel counting method in Adobe Photoshop. Reduced fibronectin immunostaining was observed in CPA after incubation with uNK-CM (Figure 4B; $P<0.05)$. A small but non-significant reduction in laminin expression was noted but there was no change in collagen IV expression (Figure 4B). 
Myometrial arteries cultured with uNK-CM were immunostained with antibodies to collagen IV, laminin, fibronectin or elastin and assessed qualitatively (Figures 4C-4F). A marked reduction in immunoreactivity was observed in each case, along with the loss of discrete, organised ECM layers. Furthermore, addition of a broad spectrum matrix metalloproteinase 350 (MMP) inhibitor (NNGH) to the uNK-CM abrogated the effect.

\section{uNK cell derived factors enhance trophoblast-associated vascular remodelling}

To determine whether uNK pre-treatment of SpA was sufficient to allow invasion of the vessel by trophoblast cells, SpA were incubated in uNK-CM prior to addition ofSGHPL4 extravillous trophoblast-like cells for a further incubation period. The number of invading SGHPL4 cells per tissue section was not altered when arteries were pre-treated with uNKCM (Figure 5C). Interestingly, pre-treatment of SpA with uNK-CM enhanced trophoblastassociated disruption of VSMC layers and loss of VSMCs (anuclear area) after 24h (Figures $5 \mathrm{~A}, 5 \mathrm{~B})$; loss of VSMCs was not observed when SpA were treated with uNK-CM in the

360 absence of trophoblast cells. In addition, this effect was not seen at 48h, implying that priming the SpA with uNK-CM did not confer invading trophoblasts with a significant long term advantage in this model. 


\section{Discussion}

365 During the first twenty weeks of gestation, uterine SpAs undergo a progressive wave of remodelling, whereby medial VSMCs are replaced by EVT embedded in a fibrinoid-rich matrix. Despite extensive disruption of arterial wall structure, vascular integrity is maintained and blood flow to the materno-fetal interface is enhanced. The initial stages of remodelling occur in the absence of EVT and include vessel dilatation, endothelial cell vacuolation and

370 VSMC disorganisation $(2,8)$. Using two ex vivo vessel models we demonstrate for the first time in humans that uNK cell derived factors, in particular Ang-2 and proteases, play a significant role in VSMC separation and disorganisation.

Vascular SMC organisation is maintained by cell-cell adhesion and ECM; thus efficient 375 vascular transformation requires both alterations in cell contacts and ECM remodelling. Two ex vivo vessel models, chorionic plate arteries and non-pregnant myometrial arteries, were used to investigate the role of angiogenic growth factors and cell culture supernatants on three aspects of VSMC disorganisation; separation, rounding and misalignment. Ang-1, Ang2 , IFN- $\gamma$ and VEGF-C induced VSMC disorganisation in both vessel types, while VEGF-A

380 and TGF- $\beta 1$ had no effect. In chorionic plate arteries, uNK cells derived from pregnancies at 8-10 weeks gestational age also induced VSMC changes, but no change in VSMC morphology was observed using supernatants derived from cells recovered at 12-14 weeks gestation. We have previously demonstrated that higher levels of Ang-1, Ang-2 and VEGF-C are secreted from uNK cells at 8-10, compared with 12-14 weeks gestation (19), which may

385 account for the functional gestational age differences that were observed. In addition to causing alterations in VSMC morphology and organisation, uNK-CM also altered expression levels of several ECM components of the vessel wall. Uterine NK cells are a major source of MMPs within the early pregnancy decidua $(10,22)$ and inhibition of MMP activity with a pan MMP inhibitor abrogated the effects of uNK-CM on myometrial artery VSMC organisation

390 and ECM components. Incubation of chorionic plate arteries with uNK-CM and neutralising antibodies to Ang-2 partially abrogated the effect of uNK-CM on VSMC disorganisation, while neutralising antibodies to Ang-1, IFN- $\gamma$ or VEGF-C had less or no effect. These data suggest that UNK cells initiate VSMC separation and ECM degradation in SpA remodeling via the secretion of Ang-2 and MMPs.

Interestingly, pre-treatment of SpA with uNK-derived factors did not significantly increase the number of trophoblast cells invading the vessel wall within the timeframe of our 
experiments; however, trophoblast invasion is reportedly focal in nature, with multiple cells colonising small areas of the vascular wall (11), and optimal trophoblast invasion is observed in vitro after 72-96 hours (29), making differences in invasion in our pre-treatment model more difficult to detect. Despite this, trophoblast-associated disruption of VSMC layers and loss of VSMCs were enhanced by pre-treatment with uNK-CM, demonstrating that uNK cells can promote trophoblast-mediated remodelling events.

405 Whilst uNK cells undoubtedly play a role in initiating remodelling events, first trimester EVT also secrete MMPs $(30,31)$ and angiogenic growth factors (25). Hence, EVT are also equipped to induce vascular destabilisation, which may explain our observation that EVTCM increased some parameters of VSMC disruption in the chorionic plate artery model. However, EVT-CM did not induce significant destabilisation of myometrial arteries, which

410 may reflect differences in the two vessel models used. Chorionic plate arteries are thicker walled, lack an internal elastic lamina, contain a higher proportion of collagen fibres and their VSMCs are more loosely arranged. This arrangement, where the VSMC are held in less rigid alignment, could leave cells more susceptible to the effects of vasoactive factors and explain why uNK-CM and EVT-CM had more potent effects on chorionic plate arteries than 415 myometrial SpA.

While some differences exist between the two vessel models chosen as they each served a distinct purpose. Chorionic plate arteries are easily obtained from term placenta and are reasonably consistent in size and structure. Therefore they allow a larger number of factors to

420 be tested on the same vessel. The results of the chorionic plate artery model then informed experiments using the more physiologically relevant non-pregnant myometrial arteries which are much smaller in size, technically difficult to obtain as well as it being more difficult to obtain hysterectomy samples from pre-menopausal women. The general consistency in results obtained between the two vessel types confirms the applicability of this approach.

425

The observation that $\mathrm{CM}$ derived from uNK/EVT co-cultures is less bioactive than CM derived from uNK cell cultures alone, highlights the importance of spatio-temporal regulation of different cell types during sequential remodelling events, and might explain why decidual leukocytes initiate vascular disruption prior to the arrival of EVT (10). We have reported that $430 \mathrm{CM}$ from uNK cell/EVT co-cultures contains reduced levels of Ang-1 and VEGF-C compared with expected levels based on secretion by cultures of uNK cells or EVT alone 
(26). This suggests that there is a negative feedback loop between uNK cells and EVT that limits the local secretion of angiogenic growth factors, perhaps limits the rate of the spiral artery remodelling process.

435

A role for pbNK cells as mediators of remodelling in several vascular beds has previously been alluded to, although their mechanism of action has never been addressed. PBNK cells have been shown to regulate arteriogenesis in a mouse model of hind limb ischemia (32), and they can promote the development of early-stage atherosclerotic lesions in LDL receptor null 440 mice (33). Our study highlights the unique phenotype of CD56 ${ }^{+} \mathrm{NK}$ cells isolated from the pregnant uterus, as soluble factors secreted by pbNK cells did not induce remodelling in myometrial SpA.

Based on our findings we propose a model whereby uNK cells surround unremodelled SpA 445 in early pregnancy, and secrete Ang-1, Ang-2, VEGF-C, IFN- $\gamma$ and MMPs to modulate cellcell and cell-ECM interactions. This allows VSMC to alter their shape and alignment within the arterial wall, disrupting the tightly packed layers. These changes make the arteries more penetrable to EVT, which colonise the wall and cause further disruption, allowing them to efficiently degrade the remaining ECM (31) and replace residual vascular cells. As uNK cells 450 are found predominantly in decidua, they may provide a physiological mechanism for limiting the depth of trophoblast invasion: diffusion of vasoactive factors released by decidual uNK cells may prime superficial myometrial SpA for trophoblast invasion, but failure of these factors to diffuse further into the myometrium may leave the deeper arterial segments refractory to colonisation. 


\section{Acknowledgements}

The authors would like to thank Amgen for the peptibody AMG 386 neutralising antibody and the research midwives team at the Royal Victoria Infirmary for help consenting and collecting samples. We also thank all those women who donated tissues to be used for these

460 studies. This work was supported by a grant from the BBSRC (BB/E016790/1).

\section{Author contribution}

$\mathrm{AR}$ - performed experiments; wrote manuscript

LKH - performed experiments; wrote manuscript

465 BAI - performed experiments

GEL - designed study, wrote manuscript

MMA - performed experiments

JDA - designed study, wrote manuscript

PNB - designed study

470 SCR - designed study, collected samples

JNB - designed study, wrote manuscript 


\section{References}

475 1. Ball, E., Bulmer, J.N., Ayis, S., Lyall, F., and Robson, S.C. (2006) Late sporadic miscarriage is associated with abnormalities in spiral artery transformation and trophoblast invasion. J Pathol 208, 535-542

2. Pijnenborg, R., Vercruysse, L., and Hanssens, M. (2006) The uterine spiral arteries in human pregnancy: facts and controversies. Placenta 27, 939-958

480 3. Lyall, F. (2002) The human placental bed revisited. Placenta 23, 555-562

4. Barker, D.J., Osmond, C., Golding, J., Kuh, D., and Wadsworth, M.E. (1989) Growth in utero, blood pressure in childhood and adult life, and mortality from cardiovascular disease. BMJ 298, 564-567

5. Geelhoed, J.J.M., and Jaddoe, V.W.V. (2010) Early influences on cardiovascular and renal 485 development. Eur J Epidemiol 25, 677-692

6. Nuyt, A.M., and Alexander, B.T. (2009) Developmental programming and hypertension. Curr Opin Nephrol Hypertens 18, 144-152

7. Downes Gastrich, M., Faro, R., and Rosen, T. (2010) Markers of preeclampsia and the relationship to cardiovascular disease: review of the twenty-first century literature. $J$ Matern

$490 \quad$ Fetal Neonatal Med 23, 751-769

8. Craven, C.M., Morgan, T., and Ward, K. (1998) Decidual spiral artery remodelling begins before cellular interaction with cytotrophoblasts. Placenta 19, 241-252

9. Kam, E.P., Gardner, L., Loke, Y.W., and King, A. (1999) The role of trophoblast in the physiological change in decidual spiral arteries. Hum Reprod 14, 2131-2138

495 10. Smith, S.D., Dunk, C.E., Aplin, J.D., Harris, L.K., and Jones, R.L. (2009) Evidence for immune cell involvement in decidual spiral arteriole remodeling in early human pregnancy. Am J Pathol 174, 1959-1971

11. Crocker, I.P., Wareing, M., Ferris, G.R., Jones, C.J., Cartwright, J.E., Baker, P.N., and Aplin, J.D.(2005) The effect of vascular origin, oxygen, and tumour necrosis factor alpha on 500 trophoblast invasion of maternal arteries in vitro. J Pathol 206, 476-485

12. Leonard, S., Murrant, C., Tayade, C., van den Heuvel, M., Watering, R., and Croy, B.A. (2006) Mechanisms regulating immune cell contributions to spiral artery modification -- facts and hypotheses -- a review. Placenta 27, S40-46

13. van der Heijden, O.W., Essers, Y.P., Spaanderman, M.E., De Mey, J.G., van Eys, G.J., 505 and Peeters, L.L. (2005) Uterine artery remodeling in pseudopregnancy is comparable to that in early pregnancy. Biol Reprod 73, 1289-1293 
14. Guimond, M.J., Wang, B., and Croy, B.A. (1998) Engraftment of bone marrow from severe combined immunodeficient (SCID) mice reverses the reproductive deficits in natural killer cell-deficient tg epsilon 26 mice. J Exp Med 187, 217-223

510 15. Ashkar, A.A., Di Santo, J.P., and Croy, B.A. (2000) Interferon gamma contributes to initiation of uterine vascular modification, decidual integrity, and uterine natural killer cell maturation during normal murine pregnancy. J Exp Med 192, 259-270

16. Lash, G.E., Robson, S.C., and Bulmer, J.N. (2010) Functional role of uterine natural killer (uNK) cells in human early pregnancy decidua. Placenta 31, S87-92

515 17. Bulmer, J.N., Morrison, L., Longfellow, M., Ritson, A., and Pace, D. (1991) Granulated lymphocytes in human endometrium: histochemical and immunohistochemical studies. Hum Reprod 6, 791-798

18. Li, X.F., Charnock-Jones, D.S., Zhang, E., Hiby, S., Malik, S., Day, K., Licence, D., Bowen, J.M., Gardner, L., King, A., Loke, Y.W., and Smith, S.K. (2001) Angiogenic growth

520 factor messenger ribonucleic acids in uterine natural killer cells. J Clin Endocrinol Metab 86, 1823-1834

19. Lash, G.E., Schiessl, B., Kirkley, M., Innes, B.A., Cooper, A., Searle, R.F., Robson, S.C., and Bulmer, J.N. (2006) Expression of angiogenic growth factors by uterine natural killer cells during early pregnancy. J Leukoc Biol 80, 572-580

525 20. Distler, J.H., Hirth, A., Kurowska-Stolarska, M., Gay, R.E., Gay, S., and Distler, O. (2003) Angiogenic and angiostatic factors in the molecular control of angiogenesis. Q J Nucl Med 47, 149-161

21. Ferrara, N. (2004) Vascular endothelial growth factor: basic science and clinical progress. Endocr Rev 25, 581-611

530 22. Naruse, K., Lash, G.E., Innes, B.A., Otun, H.A., Searle, R.F., Robson, S.C., and Bulmer, J.N. (2009) Localization of matrix metalloproteinase (MMP)-2, MMP-9 and tissue inhibitors for MMPs (TIMPs) in uterine natural killer cells in early human pregnancy. Hum Reprod 24, $553-561$

23. Sweeney, M., Jones, C.J., Greenwood, S.L., Baker, P.N., and Taggart, M.J. (2006)

535 Ultrastructural features of smooth muscle and endothelial cells of isolated isobaric human placental and maternal arteries. Placenta 27, 635-647

24. Vassiliadou, N., and Bulmer, J.N. (1998) Expression of CD69 activation marker by endometrial granulated lymphocytes throughout the menstrual cycle and in early pregnancy. Immunology 94, 368-375 
540 25. Lash, G.E., Naruse, K., Innes, B.A., Robson, S.C., Searle, R.F., and Bulmer, J.N. (2010) Secretion of angiogenic growth factors by villous cytotrophoblast and extravillous trophoblast in early human pregnancy. Placenta 31, 545-548

26. Lash, G.E., Naruse, K., Robson, A., Innes, B.A., Searle, R.F., Robson, S.C., and Bulmer, J.N. (2011) Interaction between uterine natural killer cells and extravillous trophoblast cells:

545 effect on cytokine and angiogenic growth factor production. Hum Reprod 26, 2289-2295

27. Cartwright, J.E., Holden, D.P., and Whitley, G.S. (1999) Hepatocyte growth factor regulates human trophoblast motility and invasion: a role for nitric oxide. $\mathrm{Br} J$ Pharmacol 128, $181-189$

28. Choy, M.Y., and Manyonda, I.T. (1998) The phagocytic activity of human first trimester 550 extravillous trophoblast. Hum Reprod 13, 2941-2949

29. Cartwright, J.E., Kenny, L.C., Dash, P.R., Crocker, I.P., Aplin, J.D., Baker, P.N., and Whitley, G.S. (2002) Trophoblast invasion of spiral arteries: a novel in vitro model. Placenta 23, 232-235

30. Staun-Ram, E., Goldman, S., Gabarin, D., and Shalev, E. (2004) Expression and 555 importance of matrix metalloproteinase 2 and 9 (MMP-2 and -9) in human trophoblast invasion. Reprod Biol Endocrinol 2, 59

31. Harris, L.K., Smith, S.D., Keogh, R.J., Jones, R.L., Baker, P.N., Knofler, M., Cartwright, J.E., Whitley, G.S., and Aplin, J.D. (2010) Trophoblast- and vascular smooth muscle cellderived MMP-12 mediates elastolysis during uterine spiral artery remodeling. Am J Pathol $560 \quad 177,2103-2115$

32. van Weel, V., Toes, R.E., Seghers, L., Deckers, M.M., de Vries, M.R., Eilers, P.H., Sipkens, J., Schepers, A., Eefting, D., van Hinsbergh, V.W., van Bockel, J.H., and Quax, P.H. (2007) Natural killer cells and CD4+ T-cells modulate collateral artery development. Arterioscler Thromb Vasc Biol 27, 2310-2318

565 33. Whitman, S.C., Rateri, D.L., Szilvassy, S.J., Yokoyama, W., and Daugherty, A. (2004) Depletion of natural killer cell function decreases atherosclerosis in low-density lipoprotein receptor null mice. Arterioscler Thromb Vasc Biol 24, 1049-1054 
Table 1. Primary antibodies used for immunohistochemistry and immunofluorescence

\begin{tabular}{|c|c|c|c|c|c|}
\hline Antibody & Pre-Treatment $^{5}$ & Dilution & Incubation Time & Species & Clone or Cat\# \\
\hline H-caldesmon $^{1}$ & Citrate Buffer pH6.0 & $1 / 100$ & 1 hour, RT & Mouse & h-cd \\
\hline Myosin Heavy Chain ${ }^{2}$ & Citrate Buffer pH6.0 & $1 / 600$ & 1 hour, RT & Mouse & Hsm-3 \\
\hline \multirow[t]{2}{*}{ Collagen IV ${ }^{3,4}$} & ${ }^{3}$ Trypsin pH7.8 & $1 / 60$ & 1 hour, RT & Mouse & NCL-COLL-IV \\
\hline & ${ }^{4}$ None (Frozen sections) & $1: 4000$ & 1 hour, RT & Mouse & Ab6311 \\
\hline \multirow[t]{2}{*}{ Laminin $^{2,3}$} & ${ }^{3}$ Trypsin pH7.8 & $1 / 200$ & 1 hour, RT & Mouse & NCL Laminin \\
\hline & ${ }^{2}$ None (Frozen sections) & $1 / 500$ & 1 hour, RT & Mouse & LAM-89 \\
\hline \multirow[t]{2}{*}{ Elastin $^{3,4}$} & ${ }^{3}$ Trypsin pH7.8 & $1 / 60$ & 1 hour, RT & Mouse & NCL-Elastin \\
\hline & ${ }^{4}$ None (Frozen sections) & $1 / 100$ & 1 hour, RT & Rabbit & Ab23747 \\
\hline Fibronectin $^{3}$ & Trypsin $\mathrm{pH} 7.8$ & $1 / 100$ & 1 hour, RT & Mouse & Ncl-fib \\
\hline $\mathrm{CD31}^{3}$ & Citrate Buffer pH6 & $1 / 20$ & 1 hour, RT & Mouse & NCL-CD31-110 \\
\hline$\alpha$-Smooth muscle actin ${ }^{1}$ & None (frozen sections) & $1 / 100$ & 1 hour, RT & Mouse & $1 \mathrm{~A} 4$ \\
\hline Cytokeratin $7^{1}$ & None (frozen sections) & $1 / 100$ & 1 hour, RT & Mouse & OV-TL 12/30 \\
\hline
\end{tabular}

${ }^{1}$ Dako, Ely, UK; ${ }^{2}$ Sigma Chemical Co., Poole, UK; ${ }^{3}$ Leica, Newcastle upon Tyne, UK; ${ }^{4}$ Abcam, Cambridge, UK; ${ }^{5}$ Citrate buffer pre-treatments were pressure cooked for $1 \mathrm{~min}$, allowed to cool in the buffer for $20 \mathrm{~min}$; trypsin pre-treatment was at $37^{\circ} \mathrm{C}$ for $10 \mathrm{~min}$. $\mathrm{RT}=$ room temperature. 


\section{Figure Legends}

Figure 1: uNK cell-conditioned medium disrupts VSMC organisation. CPA $[\mathrm{A}-\mathrm{C}]$ or myometrial SpA [D-L] incubated with unconditioned medium, 20\% (v/v) uNK-CM, EVT$\mathrm{CM}$ or uNK/EVT CM and assessed by semi-quantitative morphological assessment for [A] rounding of VSMCs, [B] separation of VSMC layers. [C] Representative photomicrographs of CPA sections immunostained for myosin heavy chain showing rounding of VSMCs and separation of VSMC layers after culture in uNK-CM, EVT-CM or uNK/EVT-CM (8-10 weeks gestational age) (original magnification $\mathrm{x} 400$; scale bars $=50 \mu \mathrm{M}$ ). Arrows denote rounded cells while high power inserts show separation. Myometrial SpA [D-L] incubated with unconditioned medium, 20\% (v/v) uNK-CM, EVT-CM, uNK/EVT CM or pbNK-CM and assessed by semi-quantitative morphological assessment for [D, E] VSMC misalignment, $[\mathrm{G}, \mathrm{H}]$ separation and $[\mathrm{J}, \mathrm{K}]$ rounding of VSMCs. [F, I, L] Representative fluorescent immunostaining for $\alpha \mathrm{SMA}$ (green) and counterstained with propidium iodide (red) showing [F] VSMC misalignment, [I] separation of VSMC layers and [L] rounding of VSMCs. Each dot represents a different experiment and the bar represents the mean $(\mathrm{n}=6-10) ; * P<0.05$, $* * P<0.01, * * * P<0.001$; ANOVA with Fishers post-hoc test.

Figure 2: uNK cell derived growth factors disrupt VSMC organisation. [A] CPA were incubated with 10ng/ml recombinant human Ang-1, Ang-2, VEGF-C or IFN- $\gamma$ and the extent of [A] separation of VSMC layers and [B] rounding of VSMCs was assessed semiquantitatively. [C] CPA were incubated with $20 \%(\mathrm{v} / \mathrm{v}) \mathrm{uNK}-\mathrm{CM}$ and neutralising antibodies against IFN- $\gamma$, Ang-1, Ang-2 and VEGF-C and assessed semiquantitively for VSMC separation and VSMC rounding. [D] Representative sections of CPA immunostained for myosin heavy chain showing altered VSMC morphology after addition of exogenous Ang-2, IFN- $\gamma$ and VEGF-C, with partial restoration after addition of neutralising antibody to Ang-2, IFN- $\gamma$ or VEGF-C to the uNK-CM. Solid boxes show areas of increased rounding while dashed boxes show areas of increased VSMC separation. Scale bars $=100 \mu \mathrm{m}$. Each dot represents a different experiment and the bar represents the mean $(\mathrm{n}=6) ; * P<0.05, * * P<0.01$, $* * * P<0.005$; ANOVA with Fishers post-hoc test.

\section{Figure 3: uNK cell-derived growth factors disrupt spiral artery architecture.} Myometrial SpA were incubated with recombinant human growth factors $(10 \mathrm{ng} / \mathrm{ml})$ in the presence or absence of neutralising antibodies and assessed semi-quantitatively for VSMC misalignment, separation of VSMC layers and rounding of VSMCs. [A-C] Ang-1, [D-F] Ang-2, [G-I] VEGF-C, [J-L] IFN- $\gamma$. [M-O] SpA were incubated with uNK-CM \pm NNGH 
$(50 \mu \mathrm{M})$ and scored for [M] VSMC misalignment, [N] separation of VSMC layers and [O] rounding of VSMCs. Each dot represents a different experiment and the bar represents the median value $(\mathrm{n}=5-6) ; * P<0.05, * * P<0.01, * * * P<0.001$; Kruskall-Wallis.

Figure 4: uNK-CM initiates breakdown of the vascular extracellular matrix. [A] Representative photomicrographs of non-remodelled myometrial SpA from non-pregnant women immunostained for H-caldesmon, collagen IV, fibronectin, laminin, elastin or control IgG. Scale bars $=50 \mu \mathrm{M}(\mathrm{n}=10)$. [B] CPA cultured with control medium or uNK-CM were immunostained for collagen IV, fibronectin or laminin and immunostaining quantified $(n=6)$; $* P<0.05$; t-test. [C-F] Representative photomicrographs of SpA incubated with unconditioned medium containing 1.6\% (v/v) DMSO (vehicle control), $20 \%$ (v/v) uNK-CM or uNK-CM containing the MMP inhibitor NNGH $(50 \mu \mathrm{M})$ and immunostained for $[\mathrm{C}]$ collagen IV, [D] laminin, [E] elastin and [F] fibronectin (green). Nuclei were counterstained with propidium iodide (red). Scale bars $=50 \mu \mathrm{m}(\mathrm{n}=6)$.

Figure 5: uNK-CM enhances trophoblast-associated vascular remodelling. SpA were incubated with unconditioned medium (control) or $20 \%$ (v/v) uNK-CM for $48 \mathrm{~h}$. After transfer to fresh, unconditioned medium, SGHPL4 cells were seeded onto the arteries and were co-cultured for a further $24 \mathrm{~h}$ or $48 \mathrm{~h}$. [A-C] Sections of each artery were stained with propidium iodide and $[\mathrm{A}, \mathrm{B}]$ an antibody to $\alpha \mathrm{SMA}$ or $[\mathrm{C}]$ an antibody to cytokeratin-7, and were scored for evidence of [A] loss of VSMCs [B] separation of VSMC layers and [C] trophoblast invasion. Each dot represents a different experiment and the bar represents the median value $(\mathrm{n}=6) ; * P<0.05$; Kruskall-Wallis. [D-F] Arteries were immunostained with an antibody to $\alpha$ SMA (green) and nuclei were counterstained with propidium iodide (red). Scale bars $=50 \mu \mathrm{m}$. 


\section{Figure 1}

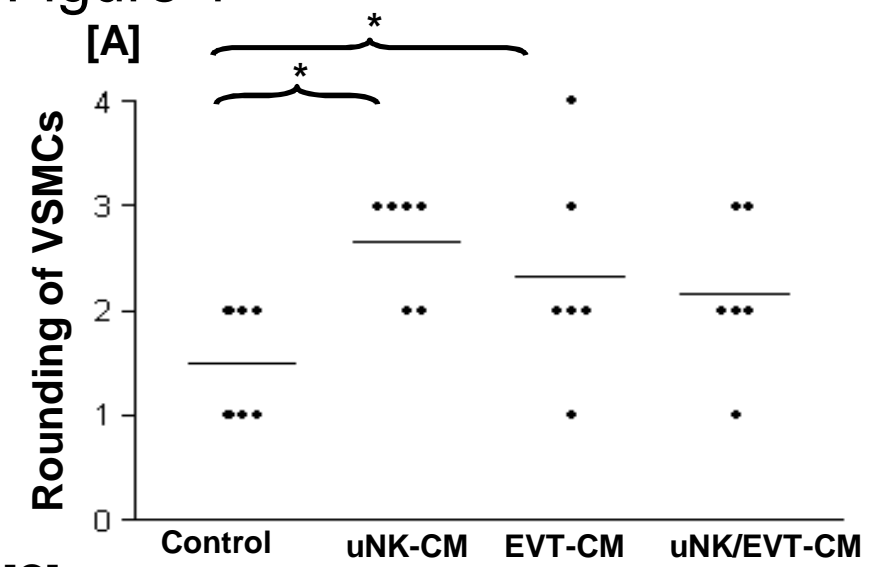

[C]

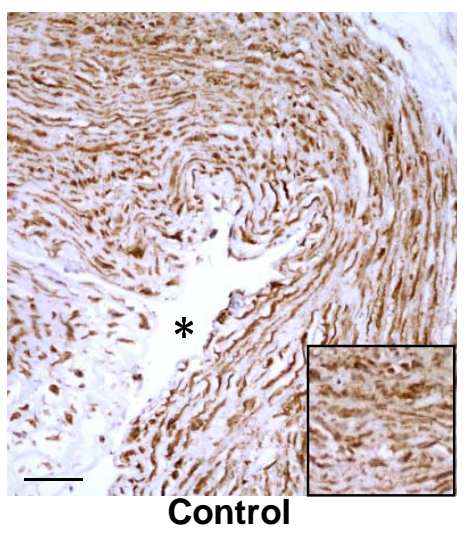

[D] VSMC misalignment

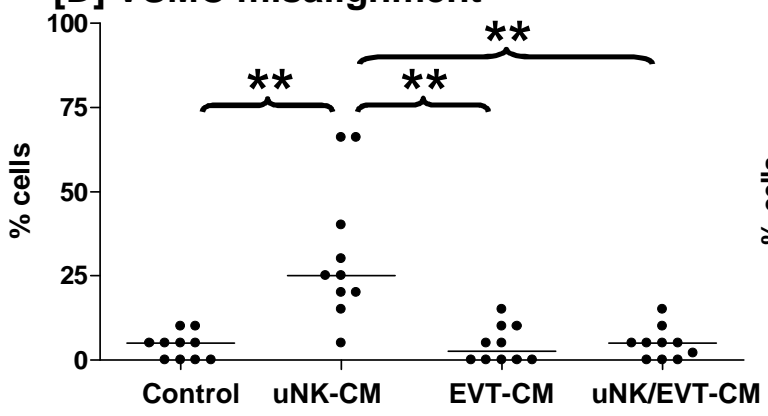

[G] Separation of VSMC layers

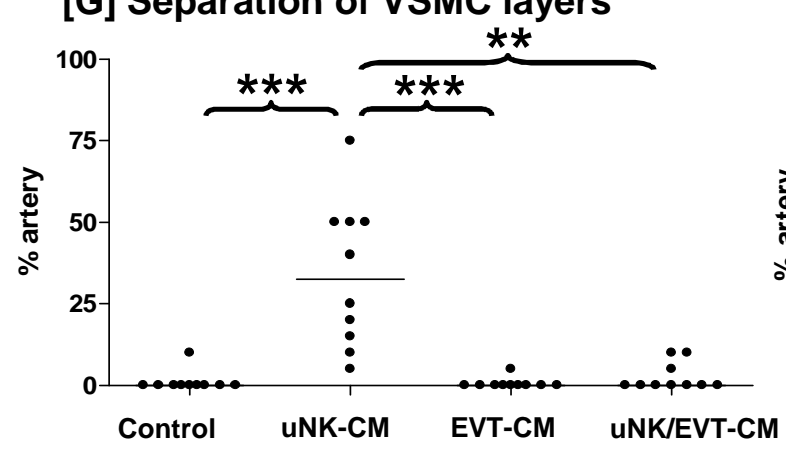

[J] Rounding of VSMCs

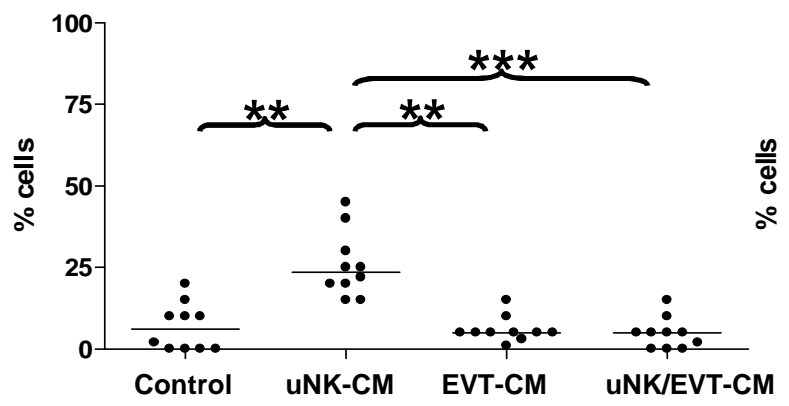

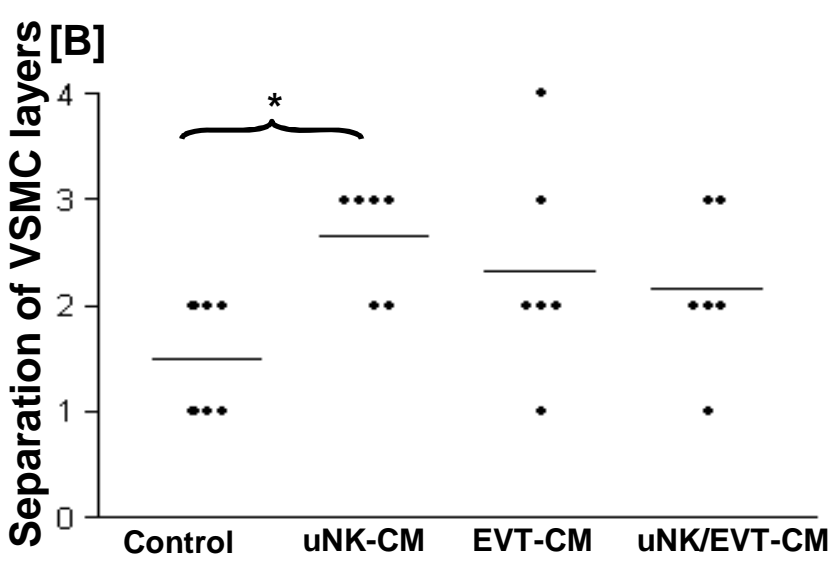

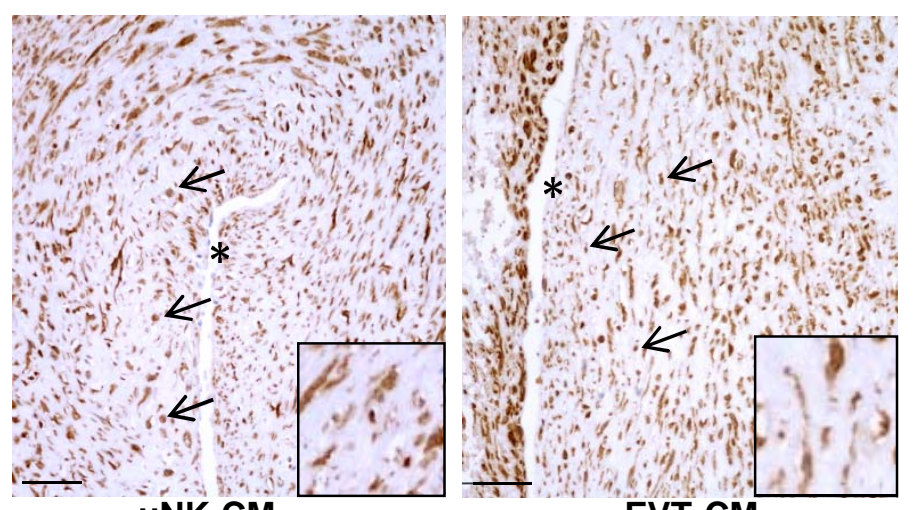

EVT-CM
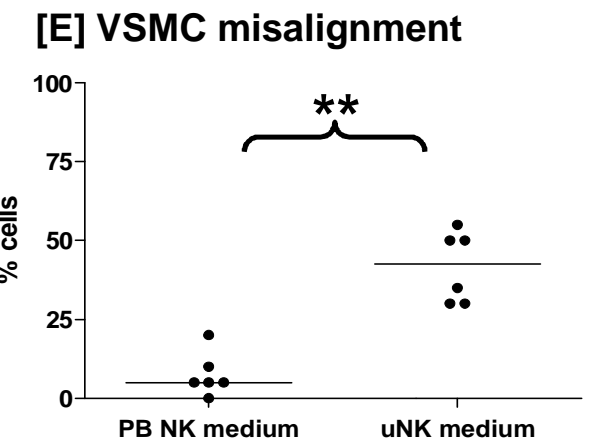

[H] Separation of VSMC layers
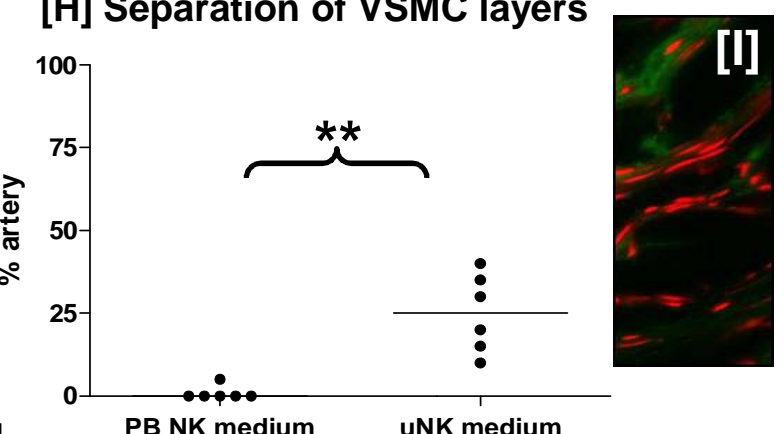

PB NK medium UNK medium

[K] Rounding of VSMCs

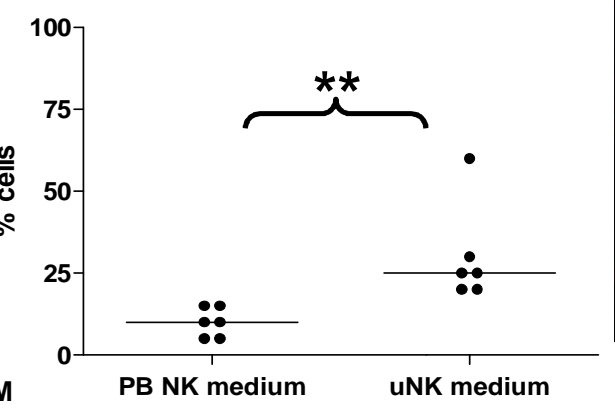

uNK/EVT-CM
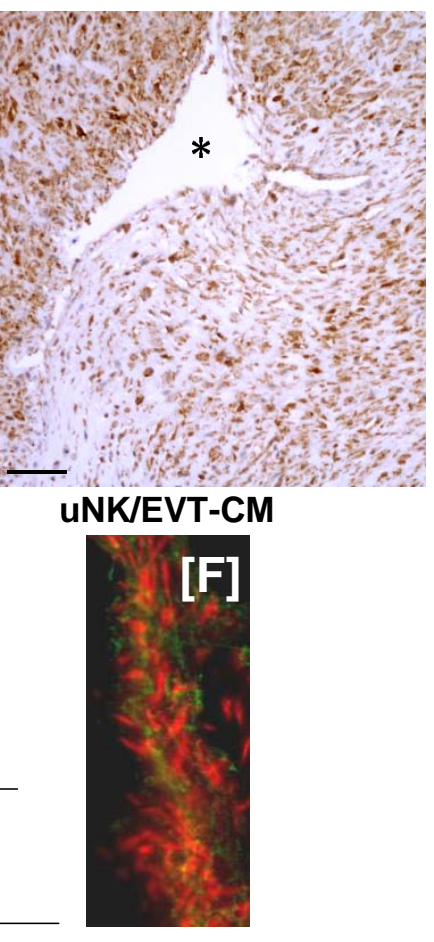

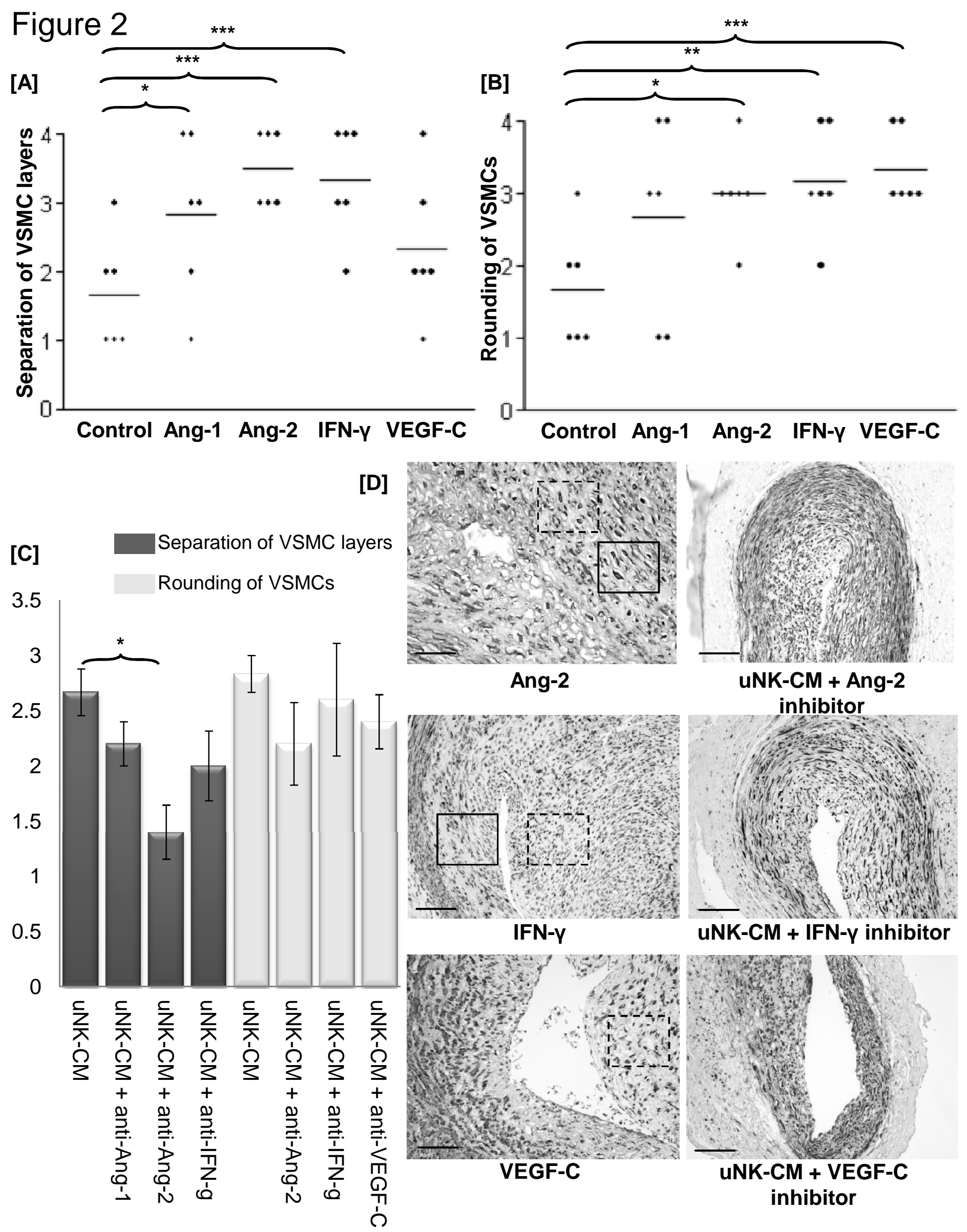
Figure 3
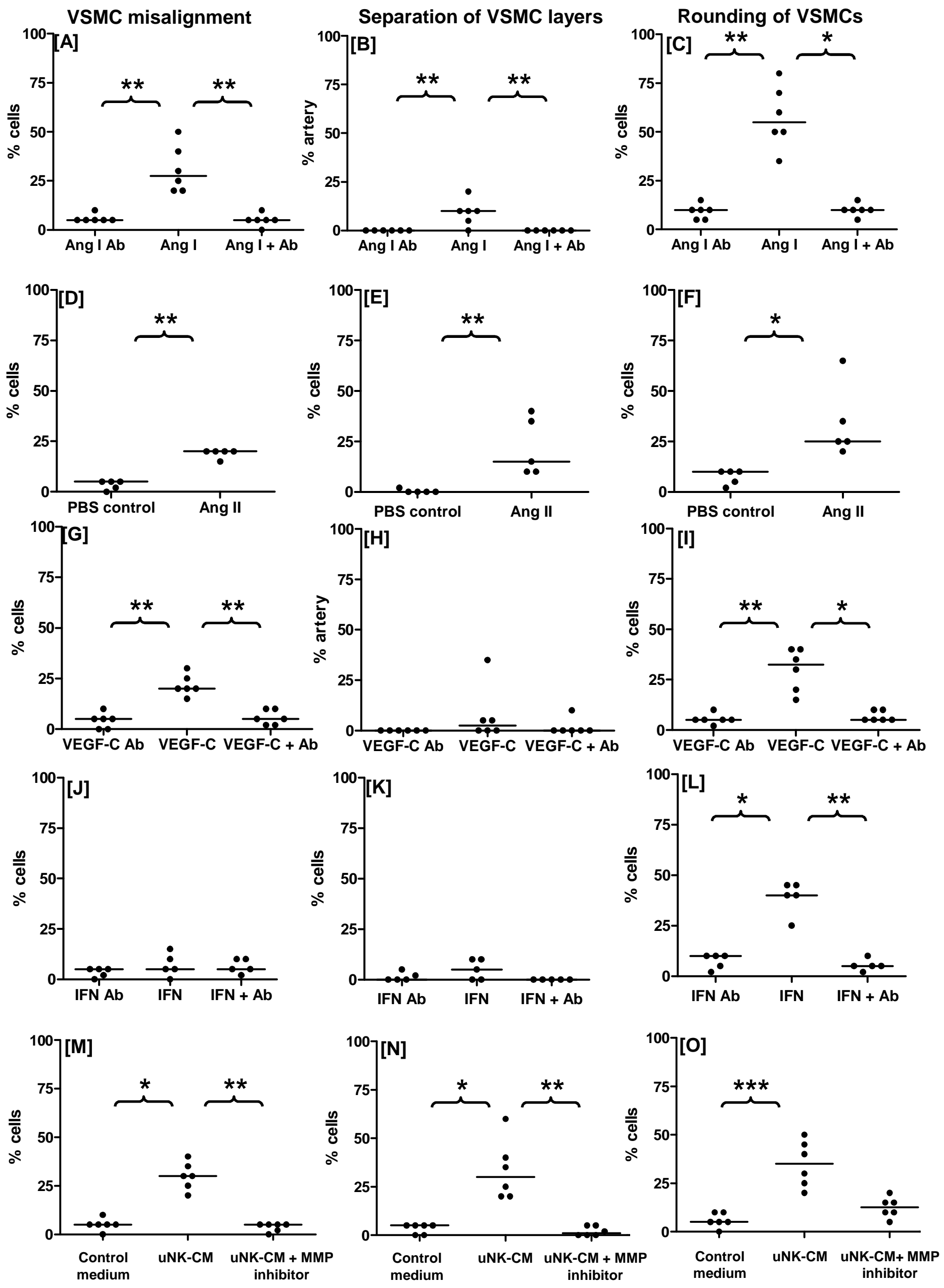
Figure 4
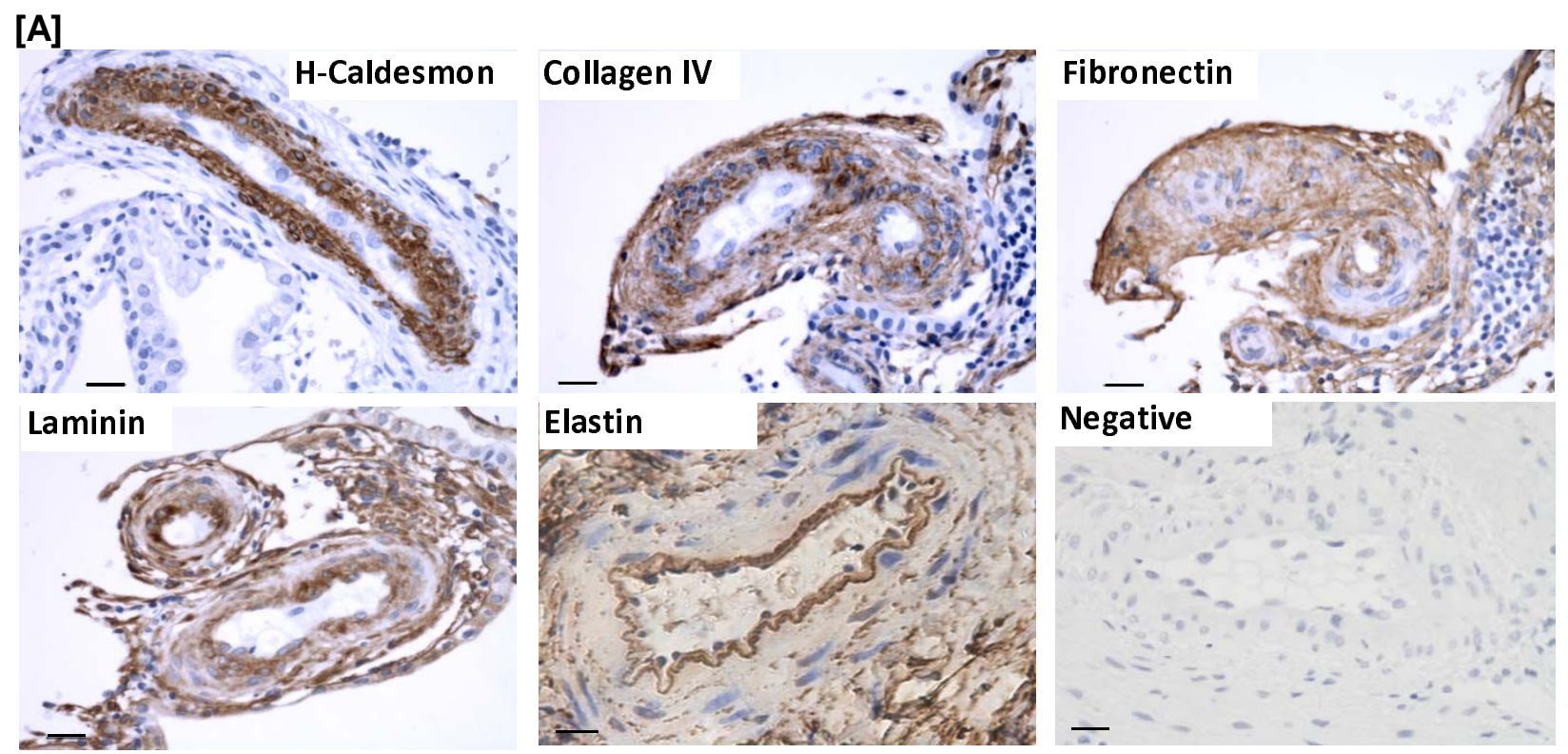

Negative
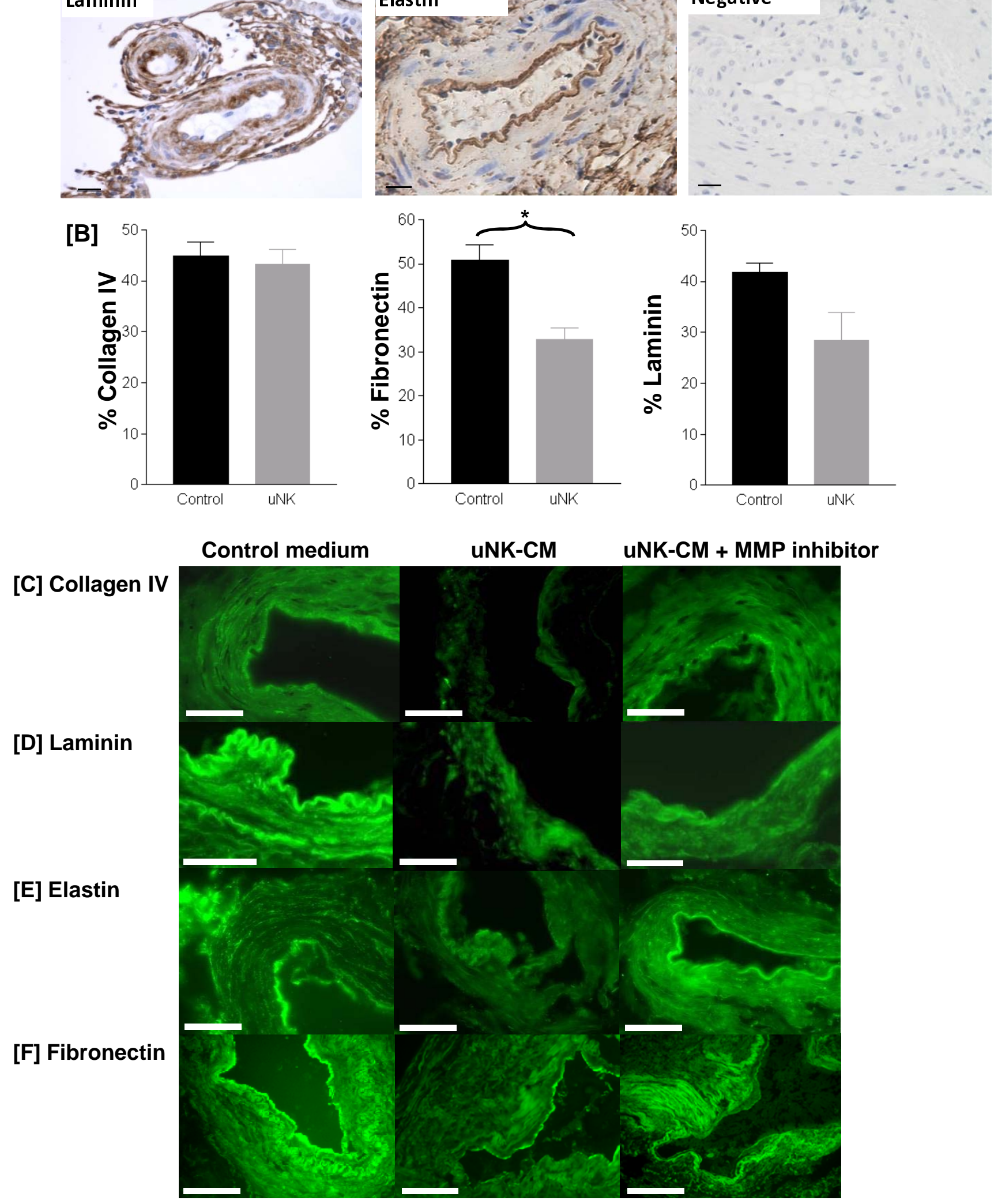
Figure 5

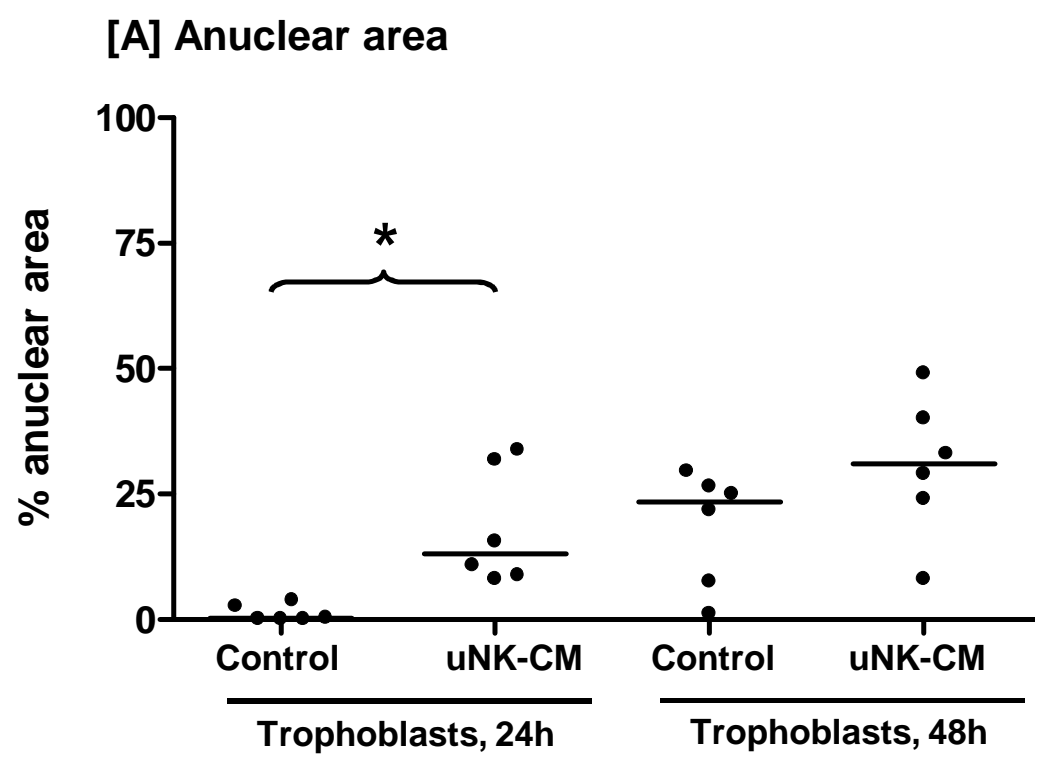

[B] Separation of VSMC layers

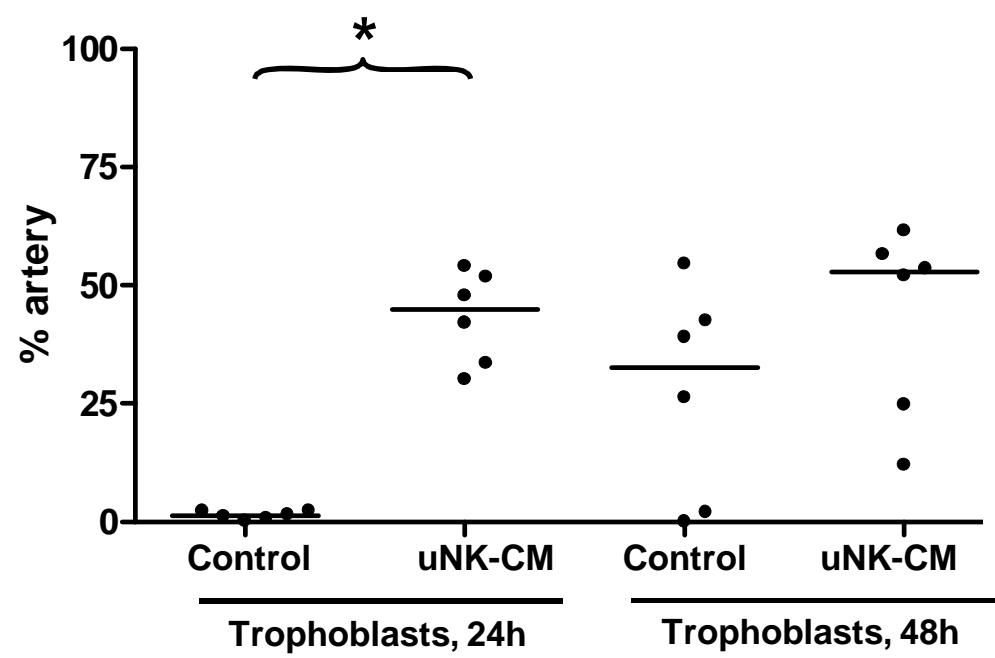

[C] Trophoblast invasion

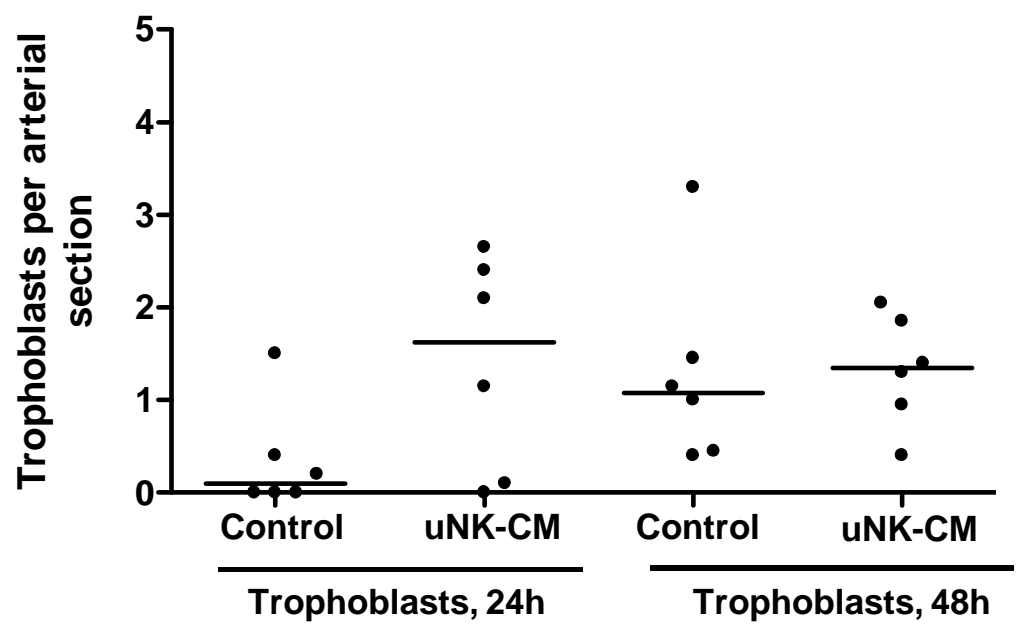

[D] Control + trophoblast cells

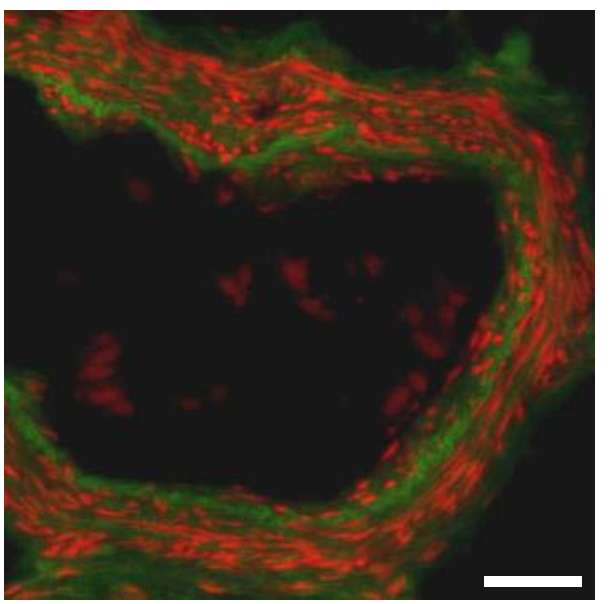

[E] uNK-CM + trophoblast cells

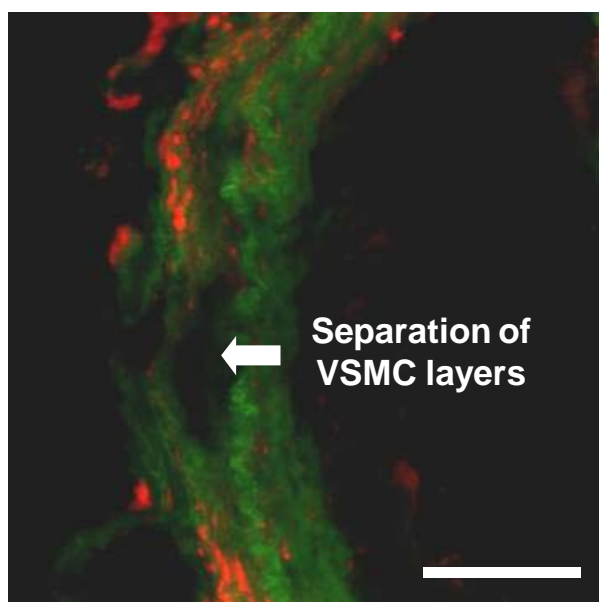

[F] uNK-CM + trophoblast cells

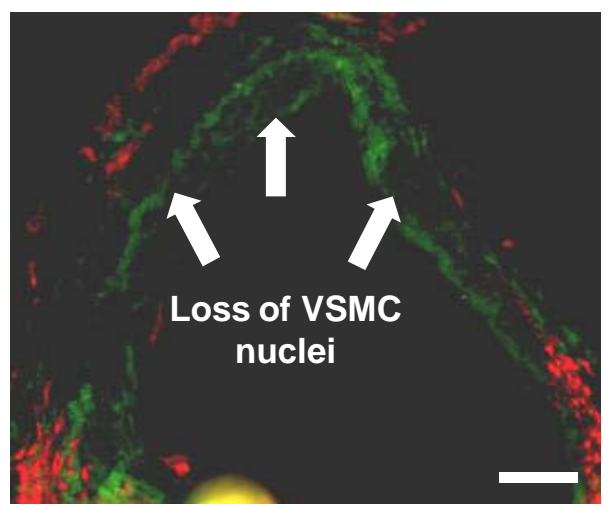

